\title{
Processing Parameters Influence on Wear Resistance Behaviour of Friction Stir Processed Al-TiC Composites
}

\author{
E. T. Akinlabi, ${ }^{1}$ R. M. Mahamood, ${ }^{1,2}$ S. A. Akinlabi, ${ }^{3}$ and E. Ogunmuyiwa ${ }^{1}$ \\ ${ }^{1}$ Department of Mechanical Engineering Science, University of Johannesburg, Auckland Park Kingsway Campus, \\ Johannesburg 2006, South Africa \\ ${ }^{2}$ Department of Mechanical Engineering, University of Ilorin, Ilorin, Nigeria \\ ${ }^{3}$ School of Mechanical, Industrial and Aeronautical Engineering, University of the Witwatersrand, Johannesburg 2050, South Africa
}

Correspondence should be addressed to E. T. Akinlabi; etakinlabi@uj.ac.za

Received 23 December 2013; Revised 20 March 2014; Accepted 24 March 2014; Published 15 June 2014

Academic Editor: Achilles Vairis

Copyright (C) 2014 E. T. Akinlabi et al. This is an open access article distributed under the Creative Commons Attribution License, which permits unrestricted use, distribution, and reproduction in any medium, provided the original work is properly cited.

Friction stir processing (FSP) being a novel process is employed for the improvement of the mechanical properties of a material and the production of surface layer composites. The vital role of the integrity of surface characteristics in the mechanical properties of materials has made the research studies into surface modification important in order to improve the performance in practical applications. This study investigates the effect of processing parameters on the wear resistance behavior of friction stir processed Al-TiC composites. This was achieved through microstructural characterization by using both the optical and scanning electron microscope (SEM), microhardness profiling, and tribological characterization by means of the wear. The microhardness profiling of the processed samples revealed an increased hardness value, which was a function of the TiC particles incorporated when compared to the parent material. The wear resistance property was also found to increase as a result of the TiC powder addition. The right combination of processing parameters was found to improve the wear resistance property of the composites produced.

\section{Introduction}

Friction stir welding (FSW) is a novel solid-state joining technique which was invented and patented by The Welding Institute in 1991. The technique was designed and initially utilized for butt and lap welding of ferrous and nonferrous metals and plastics [1]. However, over the last two decades, the technique has been extensively modified and improved with a significant growth at both technology implementation and scientific exploration leading to commercialization. This has consequently led to the scope of its application being broadened [2] and has evolved to create several new processes, among which is the friction stir processing. The schematic of the FSW process is shown in Figure 1.

The process involves clamping the workpieces together on the machine bed along the butting faces of the joint. A nonconsumable rotating tool, with a specially designed pin and shoulder, is plunged between the abutting faces of the joint and traversed along the joint line.
The friction between the tool and the workpiece generates localized heating in the vicinity of the immersed rotating pin, causing the plastic deformation of the material. In addition, the generated heat softens the material and creates a plasticized region around the plunged rotating pin, while the shoulder of the tool prevents the egress of the plasticized material from the weld. The tool meanwhile moves linearly along the joint line, causing the plasticized material to flow from the front to the back of the pin, at which point, it coalesces and forms a solid-state welded joint [3].

Friction stir welding enjoys numerous advantages over the previous conventional welding methods. These advantages are classified into two distinct categories, which are the metallurgical benefits and the environmental benefits. The metallurgical benefits include low distortion, greater weld strength, good dimensional stability and repeatability, no loss of alloying elements, excellent metallurgical properties in the joint area, good corrosion resistance, fine microstructure, and absence of cracks [4]. Some of the environmental 


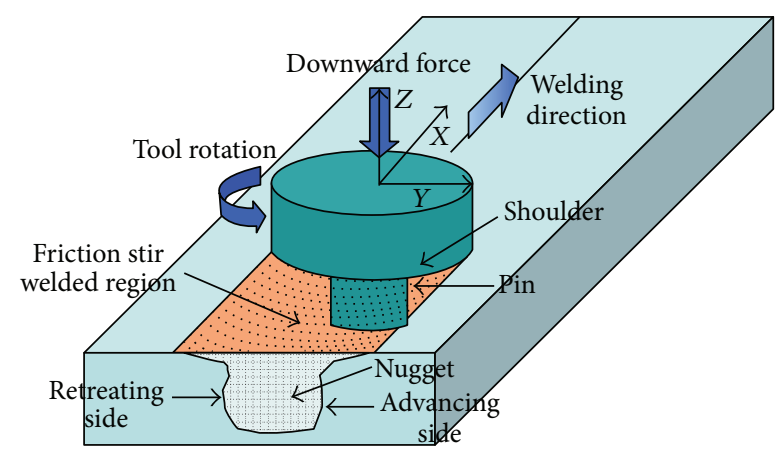

FIgURE 1: Schematic of friction stir welding process [1].

benefits include lower energy consumption compared to the conventional welding, surface cleaning, degreasing solvents, and negating harmful welding fumes and gasses and waste material [5].

FSW has been touted as being the most significant development in metal joining in a decade [1], and FSP is expected to be the evolutionary successor. It employs the same basic processing technique and tooling design as found in FSW. However, it differs in that FSW deals with joining two materials either similar or dissimilar, whereas FSP is employed to strengthen (not necessarily join) some areas of a material. Furthermore, FSP being a continuous process also employs a rotating tool comprising a pin and shoulder plunged into the area of interest.

Heat is generated by the frictional forces between the rotating tool and the substrate, with additional adiabatic heating generated from the metal deformation. The tool then traverses relatively over the substrate, causing it to coalesce. The processed zone cools without solidification (as there is no liquid), creating a defect-free recrystallized and fine grain microstructure. The advantages of friction stir processing are mainly metallurgical in nature and, as such, it is a process that can change and modify the local properties of a workpiece, without influencing the properties in the remaining part of the workpiece. Casting defects can be locally eliminated, and the microstructure thereby refined, thus improving the strength and ductility, enhancing formability, and substantially increasing corrosion resistance and fatigue life of the processed material $[6,7]$. FSP is also able to produce fine-grained microstructures through the thickness to impart super plasticity.

In FSP, there are a number of parameters, which affect the overall process. Varying these parameters can have a significant effect on the mechanical properties such as the microhardness and strength and fatigue life of the final product $[1,2]$. Aluminium and its alloys enjoy widespread applications due to many positive characteristics, among which are the favorable strength to weight ratio, corrosion resistance, and appearance. The integrity of the joint is dependent on an array of factors such as the geometry, material composition, type of joint, number of joints, and the environmental service conditions [8]. On the other hand, friction stir welding has successfully been utilized to weld all wrought aluminium alloys, across the $2 \mathrm{xxx}, 5 \mathrm{xxx}, 6 \mathrm{xxx}$, and $7 \mathrm{xxx}$ series of alloys, some of which are bordering on being classed as virtually nonweldable by fusion welding techniques. The friction stir welding process is also able to weld dissimilar aluminium alloys, whereas fusion welding may result in the alloying elements from the different alloys interacting to form deleterious intermetallics through precipitation during solidification from the molten weld pool [9].

FSP, being cutting edge and new, is an emerging technology, which has generated an enormous amount of interest in the industry, specifically in the aerospace, marine, and the automotive sector, and so forth. Mega companies which are known to be researching and utilizing FSP technology include Boeing, Phantom Works, Bombardier, Cummins, EADS Airbus, General Motors Research, Gulfstream, Hawker Beechcraft, JFE Steel, Kaiser Aluminium, Kawasaki, Lockheed Martin Corp, NASA Johnson Space Centre, NASA Langley Research Centre, Space X, and the Swedish Nuclear Fuel and Waste Management Company [1]. This growing list of companies confirms the claim of the relevance of this new technology to various applications. In addition, it predicts the imminent surge in the popularity and prevalence of FSP.

Friction stir processing is most commonly employed on aluminum and its alloys $[10,11]$; friction stir processing is often used to create aluminium matrix composites (AMC) which uses aluminium as the parent material. However, most of the research work on FSP of aluminium and its alloys reported in the literature ranged between the $1 \mathrm{xxx}, 2 \mathrm{xxx}$, $5 \mathrm{xxx}, 6 \mathrm{xxx}$, and $7 \mathrm{xxx}$ series of alloys; these are the same series which have proven successful in the FSW experiments. Typical FSP of aluminium and its alloys found in the literature include AA1050 [6, 12, 13], AA2024 [14-16], AA2095 [17], AA5083 [18-20], AA5086 [21], AA6061 [22, 23], and AA7075 [24]. It is shown that FSP technology is very effective in microstructure modification of reinforced metal matrix composite materials [11]. FSW and FSP have many advantages such as elimination of the defects such as cracks and porosity often associated with fusion welding processes and reduced distortion. In addition, it can be carried out in various positions and can join conventionally nonfusion weldable alloys and improve mechanical properties of weldable alloys. FSP has also been used to refine the grains of casting alloys [25] and to homogenize the microstructure of reinforced metal matrix composite materials [26].

Many of the processing techniques have been developed for the manufacture of particles or short fibre reinforced composites. Metal-matrix composites particularly aluminium reinforced with ceramic phases make them promising structural materials for the aerospace and automobile industries [6]. The major draw backs of such composites processed through these routes are inhomogeneous distribution (known as clustering) and improper wetting of particles which lead to poor mechanical properties [27]. An alternative approach to overcome this limitation is to produce the reinforcement in situ during processing. In the in situ process, there is no need to add the reinforcements separately; instead, the desirable reinforcement(s) and the interfaces are formed during processing itself [28-30]. Metal matrix composite (MMC) technology is one such method which can effectively increase the strength of the $\mathrm{Al}$ matrix with ceramic reinforcements like $\mathrm{SiC}, \mathrm{Al}_{2} \mathrm{O}_{3}, \mathrm{AlN}_{4} \mathrm{~B}_{4} \mathrm{C}$, and $\mathrm{TiC}$ [31]. The 
metal matrix composite almost always offers an improvement in the microstructure and hardness compared to the base metal. It should also be noted, especially in reference to this particular study, those FSP parameters such as the tool rotation and traverse speeds can have a significant effect on the material properties of the AMC [32]. This is due to the fact that these parameters have a strong influence on the grain size and dissolution of precipitates in heat treatable alloys, and these microstructural features are responsible for the material properties of the processed $\mathrm{Al}$ alloys.

There have been numerous studies on the application of the FSP process to fabricate an MMC directly on the surface of a plate in situ by processing a groove or channel on the plate which is filled with reinforcing particles [33]. However, it remains a challenge to prevent the particles from being ejected out of the groove during the FSP, and the distribution of particles is typically nonuniform unless multiple FSP passes are applied to homogenize the microstructure [34]. During FSP of composites, the parameters further influence the distribution, morphology, and break-up of the reinforcing particles $[35,36]$. The resultant composites generally exhibit better microstructure and properties because of improved wettability of particles, a clean particle-matrix interface, and strong bonds between the reinforcement and the metallic matrix [37].

Thangarasu et al. [6] investigated the microstructure and microhardness of $\mathrm{TiC}$ particulate $(\sim 2 \mu \mathrm{m})$ reinforced aluminum matrix composite (AMC) using FSP. It was established that the fabricated AA1050/TiC composite layer was well bonded to the aluminium substrate. Furthermore, the TiC particles were distributed homogeneously in the FSP zone and the hardness of the FSW zone increased by $45 \%$ higher than that of the matrix alloy; however, this was a preliminary study as only very few processing parameters were considered. Similar investigation of Bauri et al. [8] concluded that FSP could be used effectively to homogenise the particle distribution in Al-TiC in situ composites. A single pass of FSP was enough to break the particle segregation from the grain boundaries and improve the distribution. Two passes of FSP resulted in complete homogenization and elimination of casting defects. The grain size was also refined substantially after each FSP pass and finer after the second pass. Consequently, the mechanical properties improved significantly after the FSP due to the refinement in the microstructure [10]. Raaft et al. [38] concluded that the microstructure of the $\mathrm{A} 390 / \mathrm{Al}_{2} \mathrm{O}_{3}$ surface composites depends significantly on both the tool rotational and traverse speeds. Increasing the tool rotational and/or reducing the traverse speeds improves the distribution of the ceramic particulates inside the A390 matrix [39].

Aluminium matrix composites (AMCs) reinforced with ceramic phases exhibit higher strength and stiffness, improved tribological characteristics, and increased resistance to creep and fatigue. However, if the particulate is prepared by incorporating ex situ ceramic nanoparticles composites with large ceramic particles, they are prone to cracking during mechanical loading, leading to premature failure and low ductility of the composites. The mechanical properties of metal matrix composites (MMCs) can be further enhanced by decreasing the sizes of the ceramic particulates and/or matrix grains from the $\mathrm{SiC}$ or $\mathrm{TiC}$ nanoparticles [8].

The tribological properties such as wear and corrosion have been the subject of much research in the last years and the overwhelming majority of researchers suggest that corrosion resistance is better in the MMCs than the unreinforced parent material $[19,24,40-42]$. On the other hand, it is important to know that the wear resistance is usually better for the MMC than that of the base metal for all process parameters. This is due to the fact that the composite surface layer provides wear resistance and is harder than the base material. However, as this layer wears out, the wear resistance decreases dramatically and the erosive wear volume rate spikes. The processing speed is directly proportional to the wear rate of the surface layer. Hence, the best wear resistance is achieved at the slower end of the rotation and traverse speed combinations [43]. Jerome et al. [44] also conducted a preliminary study on the influence of the microstructure and experimental parameters on the mechanical and wear properties of Al-TiC surface composites; they found that the microhardness increases as the rotational speed increases which subsequently improved the wear resistance.

It is therefore believed that, with new technologies, the utilization, optimization, and expansion of FSP are limited by the lack of established process windows leading to conclusive scientific research. Detailed characterization and statistical analysis of the wear behavior of FSP of Al-TiC which can be employed to predict process windows has not been published. This paper will therefore further research by investigating the tribological properties of Al-TiC material samples produced at a range of process parameter combinations, with the aim of contributing to the global knowledge and bringing the subject of FSP a step closer to global utilization. It will also significantly broaden the aforementioned research studies in this field of study by determining the optimum parameter combination.

\section{Materials and Methods}

The FSP was employed for the development of the surface composite of aluminium alloy (AA 1050) reinforced with TiC powder of particle size range below $60 \mu \mathrm{m}$. The test samples are rectangular elements of dimension $200 \times 160 \times 3 \mathrm{~mm}^{3}$. A V-groove of about $1.5 \mathrm{~mm}$ was engraved along the length of the sheet. In this application, the area of interest is the $\mathrm{V}$-groove, which has been machined into the workpiece and filled with the $\mathrm{TiC}$ powder.

The $\mathrm{V}$-groove was machined into an area of the base plate, with the aim of strengthening the material. The powder is compressed into the groove using a pinless tool across the surface of the material. Some of the common powders often used in the literature include titanium carbide (TiC) and silicon carbide ( $\mathrm{SiC}$ ). Once the powder is compressed, a second tool, comprising a pin and shoulder, was plunged into the workpiece. The schematic of the $\mathrm{V}$-groove and compaction process is shown in Figure 2.

The selected substrate metal is AA1050; the chemical composition of the alloy is presented in Table 1. 


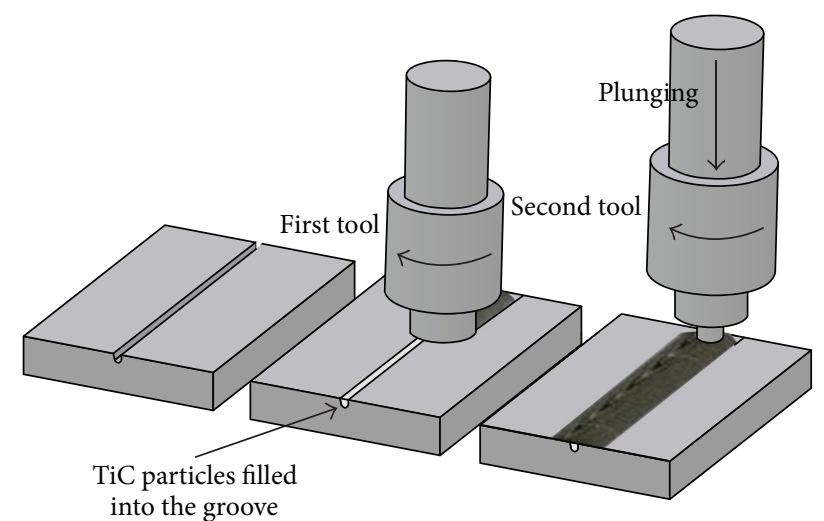

FIgURE 2: (a) A V-groove is machined into the base metal; (b) the substrate power is compressed using a pinless tool and (c) the composite is produced via FSP [6].

TABLE 1: Chemical composition of AA1050.

\begin{tabular}{ccccccccc}
\hline & $\mathrm{Al}$ & $\mathrm{Si}$ & $\mathrm{Fe}$ & $\mathrm{Cu}$ & $\mathrm{Mn}$ & $\mathrm{Mg}$ & $\mathrm{Zn}$ & $\mathrm{V}$ \\
\hline $\mathrm{AA1050}$ & 99.5 & 0.25 & 0.4 & 0.05 & 0.05 & 0.05 & 0.05 & 0.05 \\
\hline
\end{tabular}

The tools used are presented in Figure 3 and the dimensions of the tool profile are shown in Figure 4. The friction stir processing was conducted on an Intelligent Stir Welding for Industry and Research (I-STIR) Process Development System (PDS) at the Nelson Mandela Metropolitan University, Port Elizabeth, South Africa.

The workpiece was securely clamped on a rigid, smooth, and mild steel backing plate, which was able to withstand the significant perpendicular and lateral forces developed during the friction stir process. The clamping system on the I-STIR PDS system was employed to effectively clamp the aluminium alloy (AA1050) plate into position during the FSP procedure. The dimensions of the backing plate used were $650 \times 265 \times$ $25 \mathrm{~mm}^{3}$ made from mild steel plate bolted to the weld bed. The experimental setup showing the clamping fixture and the backing plate system is as presented in Figure 5 .

The weld matrix employed consists of nine (9) welds with the parameters selected according to the limit of the welding platform. A full factorial design of experiment was employed in selecting the process parameters and is presented in Table 2. The rotational speeds employed were 800, 1200 , and $1600 \mathrm{rpm}$ and the feed rates were 100, 200, and $300 \mathrm{~mm} / \mathrm{min}$ both representing the low, medium, and high settings, respectively. The Design-Expert 8 , statistical software, was employed to analyze the results obtained.

All the nine processed samples and the as-received materials were cut into the required sample sizes for material characterization such as microstructural evaluation, microhardness measurement, and the wear testing. The water jet cutting technique was employed in order to ensure that additional heat that may influence and alter the properties of the processed samples is not generated and also to ensure good result integrity. The microhardness measurement was conducted using Vickers microhardness tester of diamond indenter using $300 \mathrm{~g}$ load and a dwell time of 15 seconds.

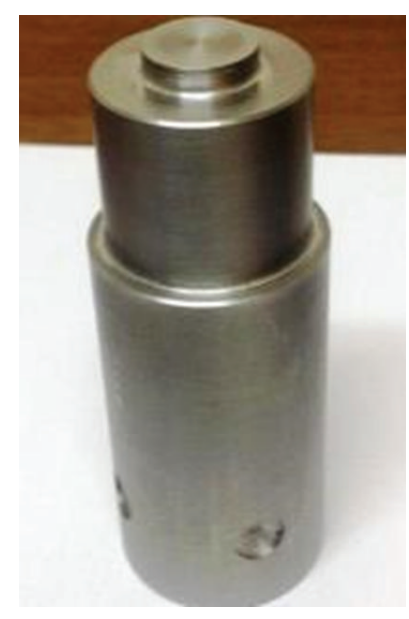

(a)

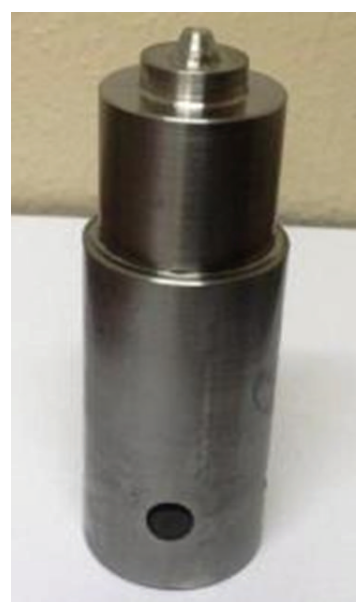

(b)
Figure 3: Schematic of the tool types, (a) pinless tool and (b) tool with a pin.

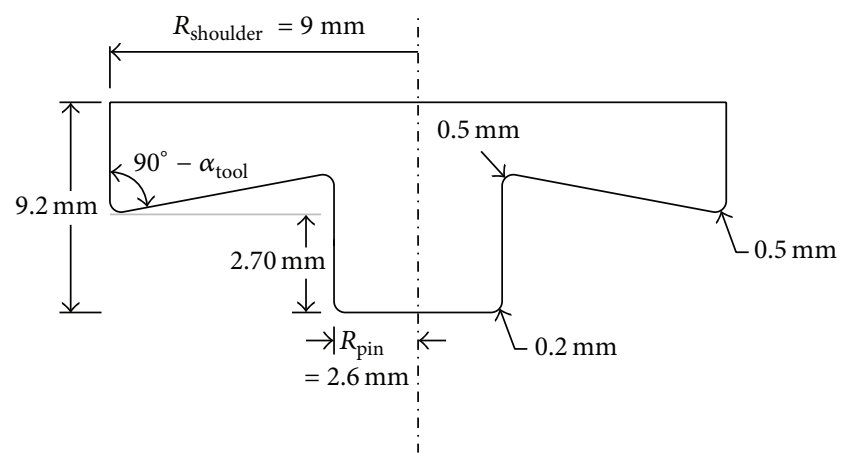

FIGURE 4: Tool dimensional drawing showing the pin and shoulder.

TABLE 2: Process parameter matrix of the FSP.

\begin{tabular}{lcc}
\hline Weld designation & Rotational speed $(\mathrm{rpm})$ & Feed rate $(\mathrm{mm} / \mathrm{min})$ \\
\hline A & 800 & 100 \\
B & 800 & 200 \\
C & 800 & 300 \\
D & 1200 & 100 \\
E & 1200 & 200 \\
F & 1200 & 300 \\
G & 1600 & 100 \\
H & 1600 & 200 \\
I & 1600 & 300 \\
\hline
\end{tabular}

The wear tests were evaluated on both the as-received and processed samples using a tribometer (CETRUMT200). The wear resistance test was performed under dry condition using a ball on disk arrangement. The material of the ball is a tungsten carbide of $10 \mathrm{~mm}$ diameter and at a load of $25 \mathrm{~N}$ with a reciprocating frequency of $20 \mathrm{~Hz}$ and at a $2000 \mathrm{~m}$ sliding distance. The wear tracks were studied under the scanning electron microscope (SEM). 


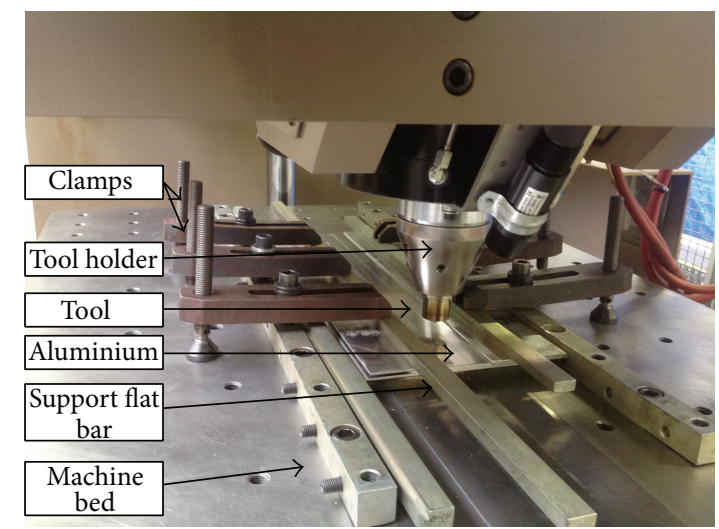

Figure 5: Experimental setup.

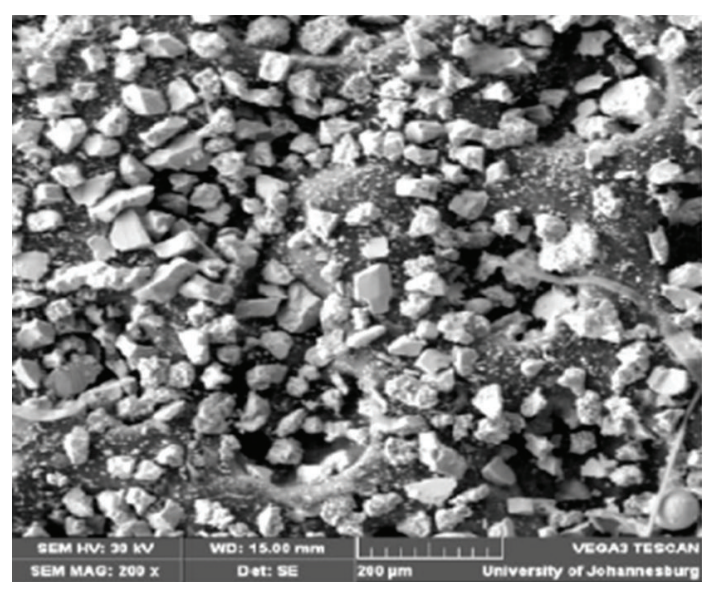

FIgURE 6: SEM micrograph of the TiC powder [45].

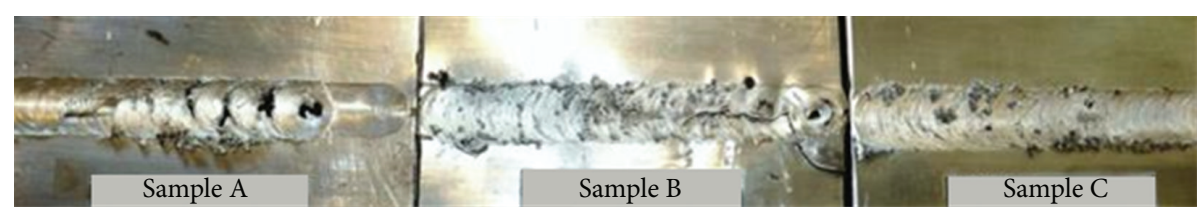

FIgUre 7: Photographs of samples A, B, and C.
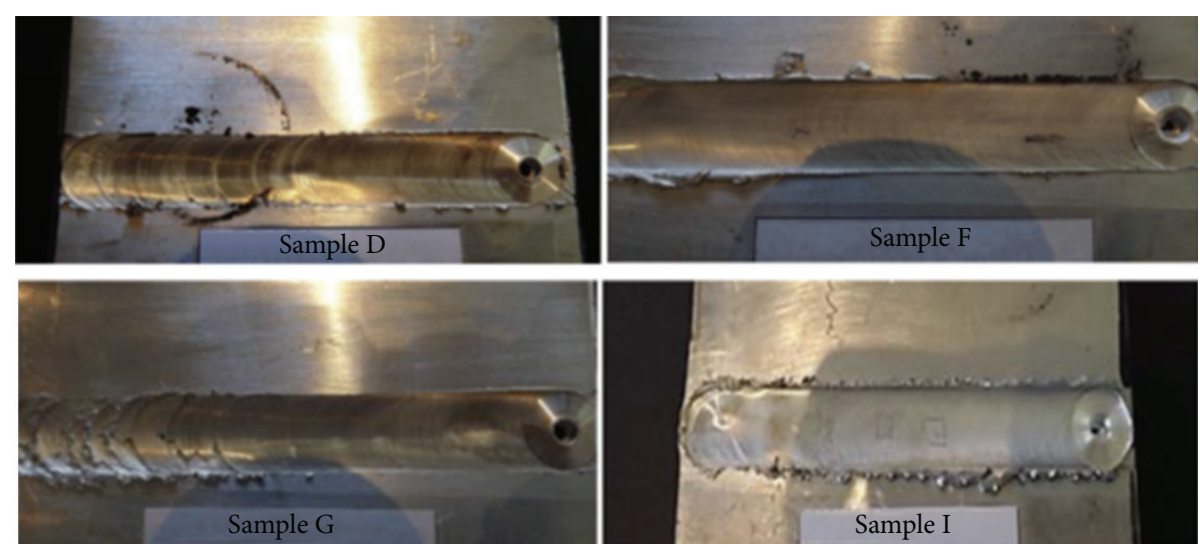

Figure 8: Photographs of samples D, F, G, and I. 


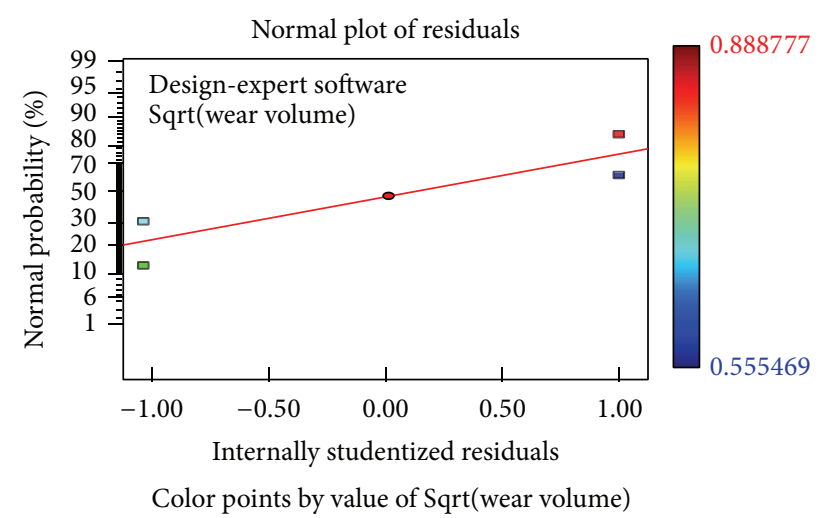

FIGURE 9: Graph of normal residual plot.

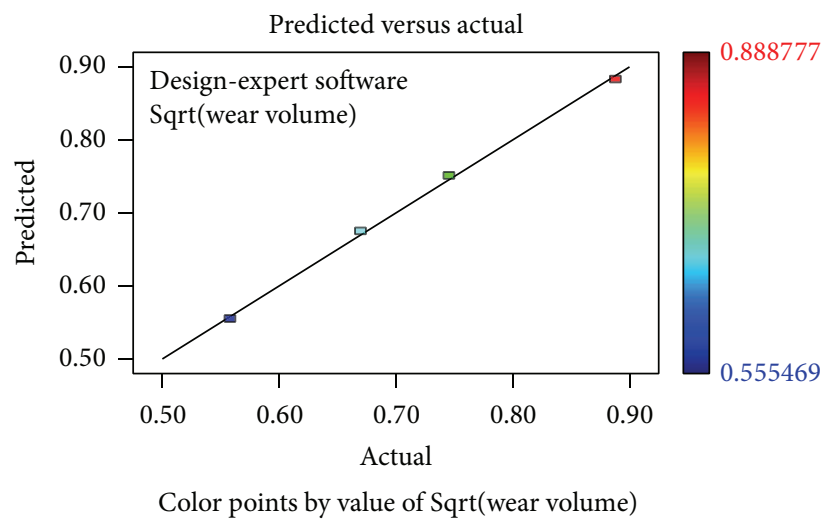

FIGURE 10: Graph of predicted versus actual experimental data.

\section{Results and Discussions}

The micrograph of the TiC powder used is shown in Figure 6. The $\mathrm{TiC}$ powder is a ball milled powder with irregular shape. The photographs of some of the processed samples are shown in Figure 7. The samples A, B, and C are characterized by visual defects as shown in Figure 7 even on repeated welds, and as such, further characterizations were not performed on them. A wormhole defect that resulted from insufficient metal flow of the advancing side above the swirl zone was seen in sample A. It was created by the unsuitable combination of the processing parameters employed in this regard. Surface galling was seen in samples B and $\mathrm{C}$, which resulted from the parameters used as well. It was visually noticeable by the galling of the metal on the top surface of the weld beneath the pin tool. Hence, the process parameters employed to produce these welds were considered inappropriate in this case. The remaining samples showed good surface appearances. Some of the photographs of the other samples are shown in Figure 8.

The results of the wear test and the average Vickers microhardness of the processed samples and the parent material are presented in Table 3.

Table 3 represents the full factorial design of experiment and the results were analyzed using Design-Expert 8, statistical software.
The analysis of variance (ANOVA) for the selected factorial model is presented in Table 4.

Further analysis of variance is shown in Table 5. The "predicted $R$-squared" of 0.9729 is in reasonable agreement with the "adjusted $R$-squared" of 0.9949 . The "adequate precision" measures the signal to noise ratio. A ratio greater than 4 is desirable. The ratio of 38.429 indicates an adequate signal and this model can be used to navigate the design space. The coefficient of the model terms is presented in Table 6 and the final model equation is shown in (1).

The model $F$-value of 294.61 implies that the model is significant. There is only a $4.12 \%$ chance that a "model $F$ value" this large could occur due to noise. Values of "Prob > $F$ " which are less than 0.0500 indicate that the model terms are significant. In this case, $A$ (rotational speed) and $B$ (feed rate) are significant model terms.

The final equation in terms of actual factors is hereby presented:

$$
\begin{aligned}
\text { Sqrt }(\text { Wear Volume })= & -0.13820+5.22006 E-004 \\
& * \text { Rotational speed } \\
& +6.22528 E-004 * \text { Feed Rate. }
\end{aligned}
$$


TABLE 3: Wear volume and microhardness results.

\begin{tabular}{lcccc}
\hline Sample designation & Rotational speed $(\mathrm{rpm})$ & Feed rate $(\mathrm{mm} / \mathrm{min})$ & Wear volume $\left(\mathrm{mm}^{3}\right)$ & Vickers microhardness $(\mathrm{HV})$ \\
\hline D & 1200 & 100 & 0.308546 & 39.9 \\
E & 1200 & 200 & 0.381606 & 41.1 \\
F & 1200 & 300 & 0.448846 & 43.5 \\
G & 1600 & 100 & 0.568903 & 46.8 \\
H & 1600 & 200 & 0.761349 & 48.1 \\
I & 1600 & 300 & 0.789925 & 51.5 \\
PM & - & - & 0.907572 & 28.9 \\
\hline
\end{tabular}

TABLE 4: Analysis of variance (ANOVA) for the selected factorial model.

\begin{tabular}{lccccc}
\hline Source & Sum of squares & df & Mean square & $F$ value & $P$ value Prob $>F$ \\
\hline Model & 0.059 & 2 & 0.030 & 294.61 & 0.0412 \\
A-Rotational speed & 0.044 & 1 & 0.044 & 434.67 & 0.0305 \\
$B$-Feed rate & 0.016 & 1 & 0.016 & 154.55 & 0.04911 \\
Residual & $1.003 E-004$ & 1 & $1.003 E-004$ & & \\
Cor total & 0.059 & 3 & & & \\
\hline
\end{tabular}

TABLE 5: Model analysis.

\begin{tabular}{lccc}
\hline Std. Dev. & 0.010 & $R$-squared & 0.9983 \\
Mean & 0.72 & Adj. $R$-squared & 0.9949 \\
C.V. \% & 1.40 & Pred. $R$-squared & 0.9729 \\
PRESS & $1.605 E-003$ & Adeq. precision & 38.429 \\
\hline
\end{tabular}

The graph of normal residual plot is shown in Figure 9 and the graph of predicted versus actual experimental data is shown in Figure 10. The residual is randomly distributed and it can also be seen that the model is in good agreement with the experimental data as shown in Figure 10.

The main effect plots of the effect of processing parameters on the wear volume loss are shown in Figure 11. The wear volume was found to increase as the rotational speed was increased as shown in Figure 11(a). Too high rotational speed for a relatively soft material such as pure aluminium tends to generate high amounts of heat that resulted in lots of mixing of the substrate and the powder. However, dilution needs to be minimized in order to improve the wear resistance of the surface; hence the advantage of using FSP as melting does not occur during the process.

The wear volume loss was also found to increase with the increase in the feed rate as shown in Figure 11(b). This can be attributed to improper melting of the TiC powder at high feed rate which would aggravate the wear action.

The surface plot showing the interaction between the rotational speed and the feed rate effect on wear volume is shown in Figure 12. It can be seen that the highest wear occurs at the highest rotational speed and the lowest feed rate. This is because of excessive heat generated at this combination of processing parameters which resulted in high dilution rate and softening of the composite. This would reduce the wear resistance property of the surface.
The microhardness results were also analyzed in a similar way and the equation of the model is presented as

$$
\begin{aligned}
\text { Sqrt (Microhardness) }= & +4.47777+1.39125 E-003 \\
& * \text { Rotational speed } \\
& +1.52838 E-003 * \text { Feed Rate. }
\end{aligned}
$$

The main effect plots of the microhardness against processing parameter are shown in Figure 13.

Figure 13(a) shows that the microhardness increases as the rotational speed increases. This can be attributed to the fact that at high feed rate, and low rotational speed, too large unmelted $\mathrm{TiC}$ powder is produced which aggravated the wear action. But as the rotational speed was increased, the volume of unmelted powder was reduced and the microhardness was improved which also improved the wear resistance property. The microhardness was found to increase as the feed rate was increased at high rotational speed as shown in Figure 13(b). This is because increasing the feed rate at high rotational speed would reduce the high heat generated and improve the microhardness property. However, the higher microhardness observed at high feed rate did not translate to high wear resistance property because, at high feed rate, the amount of unmelted $\mathrm{TiC}$ powder was increased which would increase the microhardness value but would aggravate the wear action.

The analysis of the wear tracks further confirms the effect of the processing parameters on the wear resistance behavior of the samples. Figure 14(a) shows the SEM micrograph of the wear track of sample D.

The SEM images are characterized predominantly by abrasive wear. There was moderate quantity of unmelted carbide which during the sliding wear action was rubbing against the surface of the substrate. This unmelted carbide later forms 


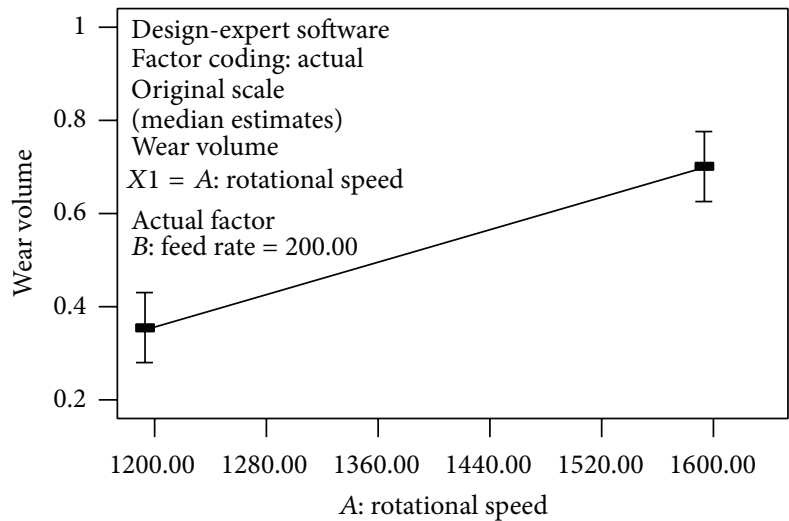

(a)

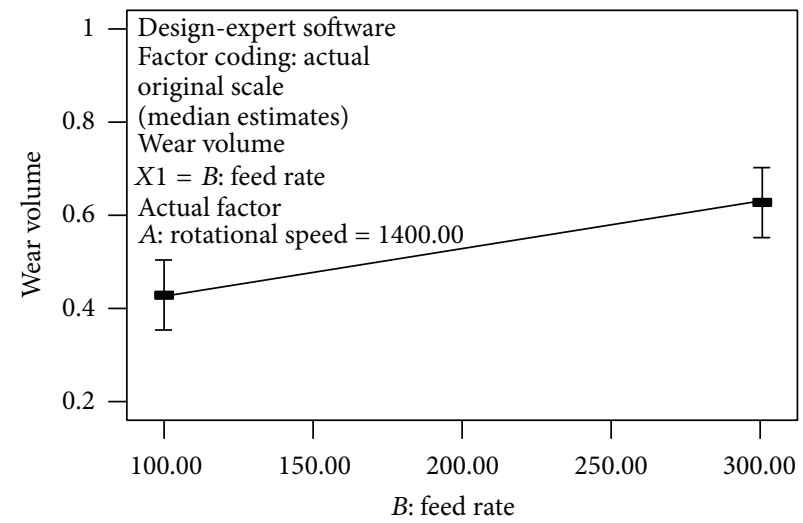

(b)

FIGURE 11: Main effect plot of (a) wear volume against rotational speed and (b) wear volume against feed rate.

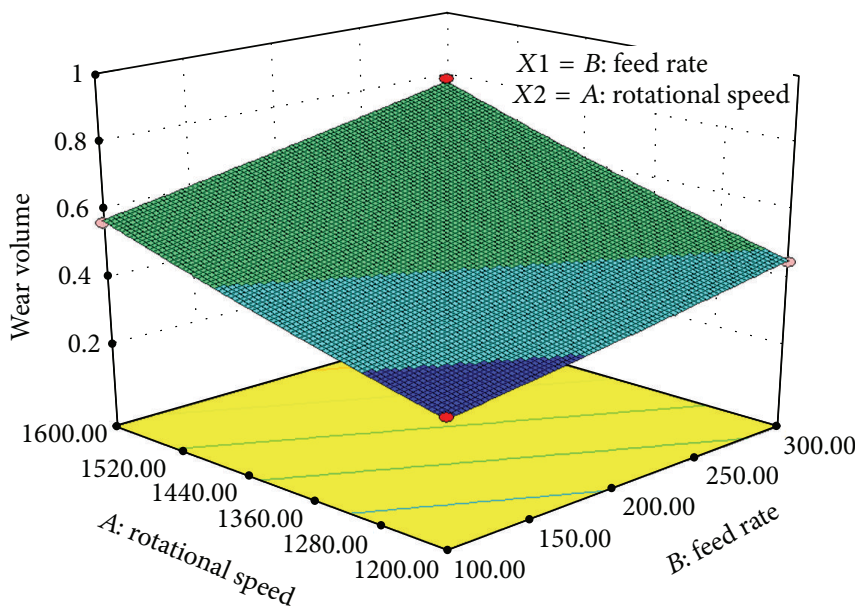

0.308546

0.789925

FIGURE 12: The surface plot of wear volume against rotational speed and feed rate.

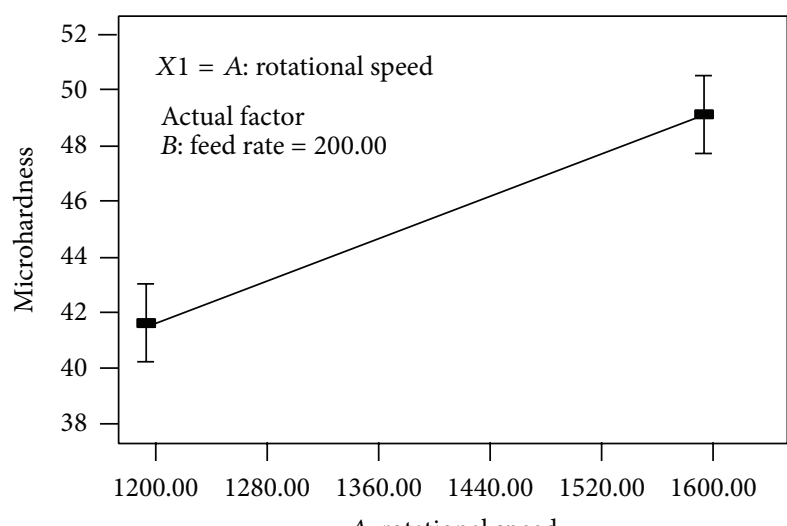

(a)

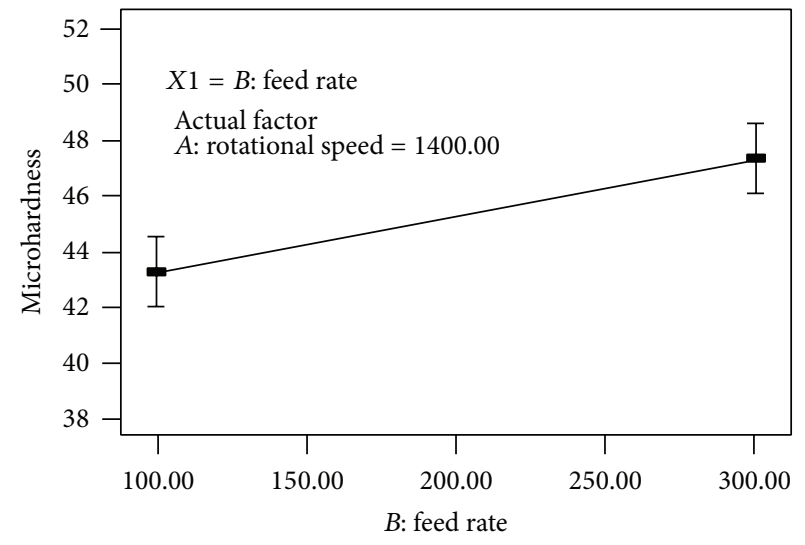

(b)

FIGURE 13: Main effect plot of (a) microhardness against rotational speed and (b) wear volume against feed rate. 
TABLE 6: The coefficient of the model terms.

\begin{tabular}{|c|c|c|c|c|c|c|}
\hline Factor & Coefficient estimate & $\mathrm{df}$ & Standard error & 95\% CI low & 95\% CI high & VIF \\
\hline Intercept & 0.72 & 1 & $5.008 E-003$ & 0.65 & 0.78 & \\
\hline$A-$ Rotational speed & 0.10 & 1 & $5.008 E-003$ & 0.041 & 0.17 & 1.00 \\
\hline$B$-Feed rate & 0.062 & 1 & $5.008 E-003$ & $-1.374 E-003$ & 0.13 & 1.00 \\
\hline
\end{tabular}

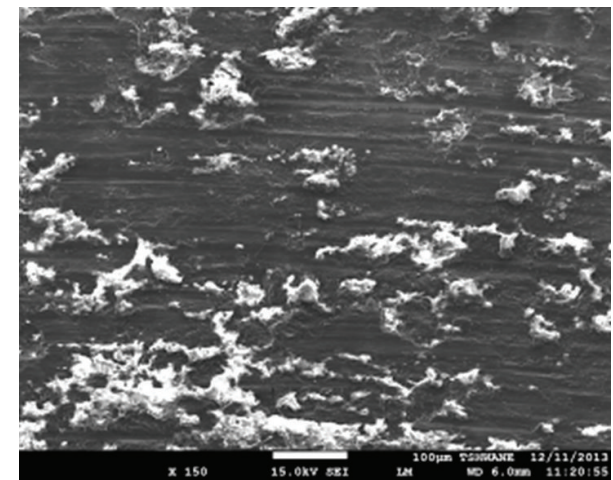

(a)

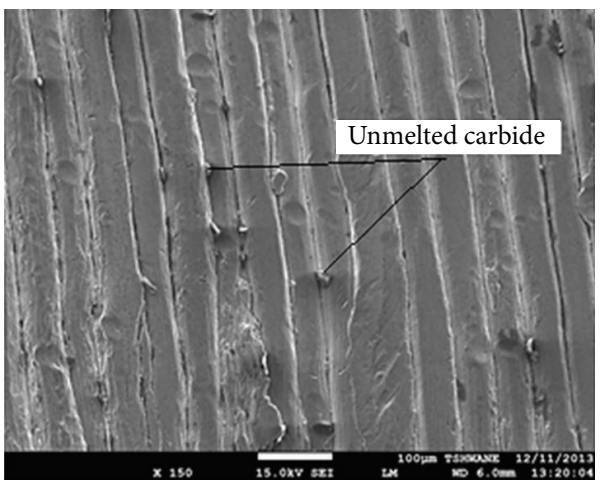

(c)

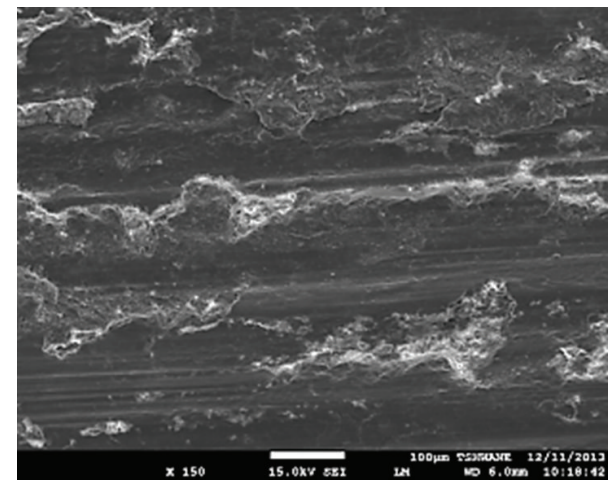

(b)

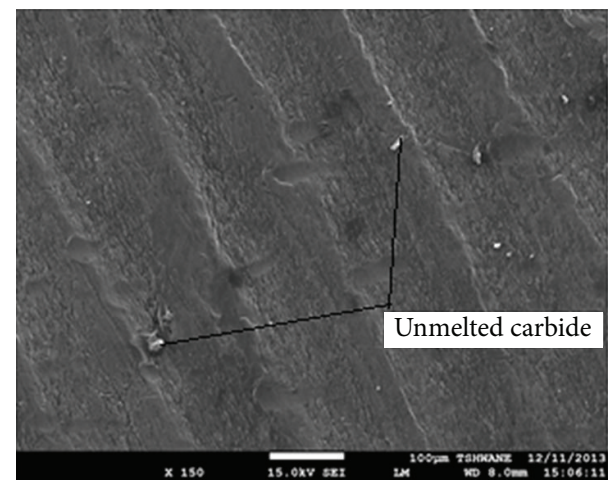

(d)

FIGURE 14: SEM micrograph of wear track of (a) sample D, (b) sample F, (c) sample G, and (d) sample I.

powder that reduces the wear action by forming a powder lubricant. As the feed rate was increased, the unmelted carbide (UMC) was also increased which aggravated the wear action by scratching deep into the substrate and forming ridges as shown in Figure 14(b). Increasing the rotational speed resulted in high heat generation which causes much of the $\mathrm{TiC}$ powder to be completely melted. This makes the composite become softer and the few remaining unmelted carbide scratches deep into the substrate and aggravated the wear action as shown in Figure 14(c). The size of the unmelted carbide increases as the feed rate was increased as shown in Figure 14(d); this makes the wear action become more severe as the sliding wear was progressing thereby producing deeper cut on the sliding surfaces.

In order to validate the developed models to demonstrate the robustness of the models, a set of experiments were performed with settings outside the ones used in the model building. The results are presented in the next section.

\section{Model Validation}

To validate models, a set of experiments were performed at the processing parameters different from the processing parameters used in the building of the model. The results are presented in Table 7. The graph of the predicted versus the experimental data is also shown in Figure 15. The graph of actual values versus actual experimental data of wear volume is shown in Figure 15(a) and that of the microhardness is shown in Figure 15(b). The graphs show that there is a good agreement between the model and the experimental data. Therefore, the models can be used to predict the wear resistance performance as well as the microhardness properties of friction stir processed $\mathrm{Al}-\mathrm{TiC}$ composites.

\section{Conclusion}

This study revealed that the friction stir processing (FSP) can be used to improve the mechanical properties of a material 
TABLE 7: Validation results.

\begin{tabular}{lcccccc}
\hline $\begin{array}{l}\text { Sample } \\
\text { number }\end{array}$ & $\begin{array}{c}\text { Rotational speed } \\
(\mathrm{rpm})\end{array}$ & $\begin{array}{c}\text { Feed rate } \\
(\mathrm{mm} / \mathrm{min})\end{array}$ & $\begin{array}{c}\text { Predicted wear } \\
\text { volume }\left(\mathrm{mm}^{3}\right)\end{array}$ & $\begin{array}{c}\text { Actual wear } \\
\text { volume }\left(\mathrm{mm}^{3}\right)\end{array}$ & $\begin{array}{c}\text { Predicted Vickers } \\
\text { microhardness }(\mathrm{HV})\end{array}$ & $\begin{array}{c}\text { Actual Vickers } \\
\text { microhardness }(\mathrm{HV})\end{array}$ \\
\hline 1 & 1400 & 150 & 0.470682 & 0.481104 & 44.29 & 44.84 \\
2 & 1300 & 180 & 0.425811 & 0.412951 & 43.05 & 42.55 \\
3 & 1000 & 300 & 0.325646 & 0.330403 & 40.04 & 40.62 \\
4 & 1500 & 100 & 0.500039 & 0.490671 & 45.13 & 45.03 \\
5 & 1500 & 150 & 0.545025 & 0.552107 & 46.16 & 46.55 \\
6 & 1700 & 100 & 0.658575 & 0.662192 & 48.94 & 49.59 \\
\hline
\end{tabular}

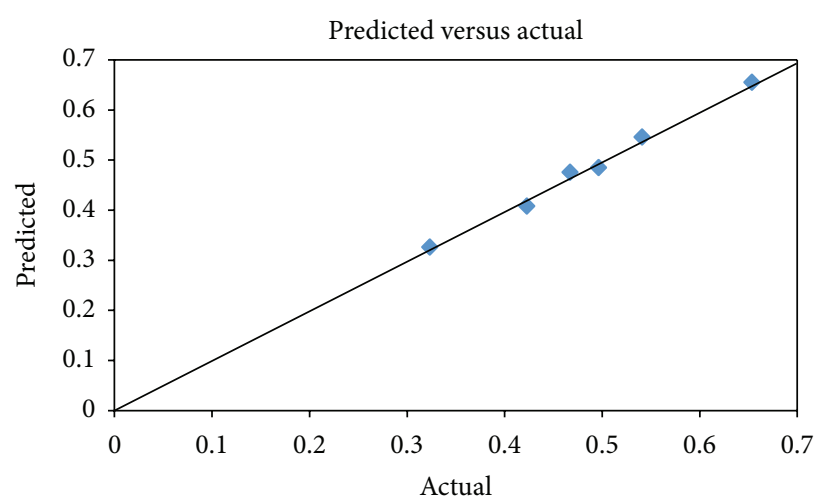

(a)

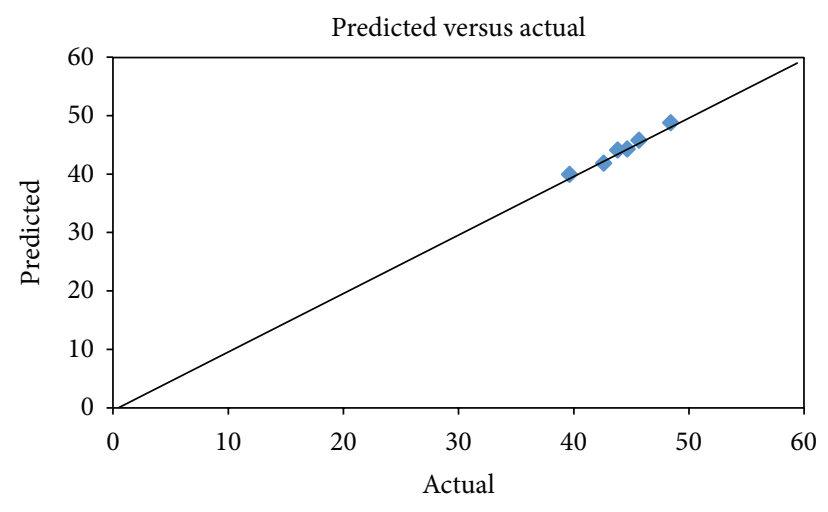

(b)

FIGURE 15: The graph of predicted versus actual experimental data of (a) wear volume and (b) Vickers microhardness.

and the production of surface layer composites. The effect of processing parameters on the wear resistance behavior of friction stir processed $\mathrm{Al}-\mathrm{TiC}$ composites was investigated in this research. The rotational speed and the feed rate effect on the wear resistance property of Al-TiC composite produced through FSP were statistically analyzed in design expert and models were developed to predict the wear volume and microhardness properties of the $\mathrm{Al}-\mathrm{TiC}$ processed samples. The models were validated through additional experiments performed at processing parameters outside the processing parameters used in building the models. The model was found to be in good agreement with the experimental data. It was shown that the right combination of these processing parameters was necessary to really improve the wear resistance property of the composite produced. At low rotational speed, there was insufficient melting of the $\mathrm{TiC}$ powder which resulted in surface defect. Also, too high rotational speed generated too high heat that resulted in lots of dilution of the $\mathrm{TiC}$ and $\mathrm{Al}$ which reduces the wear resistance property. A moderately high rotational speed of $1200 \mathrm{rpm}$ and low speed rate of $100 \mathrm{~mm} / \mathrm{min}$ produced the surface composited layer with the best wear resistance property based on the set of processing parameters considered in this study and can be considered as the optimum parameter window.

\section{Conflict of Interests}

The authors declare that there is no conflict of interests regarding the publication of this paper.

\section{Acknowledgments}

The authors would like to acknowledge the Tertiary Education Support Program funding of ESKOM South Africa and the eNtsa Research Group of Nelson Mandela Metropolitan University (NMMU), Port Elizabeth, South Africa, for allowing us to use their facility to produce the welds.

\section{References}

[1] R. S. Mishra and M. W. Mahoney, "Friction stir processing: a new grain refinement technique to achieve high strain rate superplasticity in commercial alloys," Materials Science Forum, vol. 357, no. 3, pp. 507-512, 2001.

[2] R. S. Mishra and Z. Y. Ma, "Friction stir welding and processing," Materials Science and Engineering R: Reports, vol. 50, no. 1-2, pp. 1-78, 2005.

[3] W. M. Thomas and E. D. Nicholas, "Friction stir welding for the transportation industries," Materials and Design, vol. 18, no. 46, pp. 269-273, 1997.

[4] Z. Y. Ma, "Friction stir processing technology: a review," Metallurgical and Materials Transactions A: Physical Metallurgy and Materials Science, vol. 39, no. 3, pp. 642-658, 2008.

[5] C. J. Dawes and W. Thomas, "Development of improved tool designs for friction stir welding of aluminium," in Proceedings of the International Symposium of Friction Stir Welding, Los Angeles, Calif, USA, June 1999.

[6] A. Thangarasu, N. Murugan, I. Dinaharan, and S. J. Vijay, "Microstructure and microhardness of AA1050/TiC surface 
composite fabricated using friction stir processing," Sadhana, vol. 37, no. 5, pp. 579-586, 2012.

[7] R. Mishra, Z. Ma, and J. Spowart, Friction Stir Welding and Processing II, TMS, 2003.

[8] R. Bauri, D. Yadav, and G. Suhas, "Effect of friction stir processing (FSP) on microstructure and properties of Al-TiC in situ composite," Materials Science and Engineering A, vol. 528, no. 13-14, pp. 4732-4739, 2011.

[9] E. Akinlabi, Characterisation of Dissimilar Friction Stir Welds Between 5754 Aluminium Alloy and C11000 Copper, Port Elizabeth, 2010.

[10] R. Johnson and S. Kallee, "Friction stir welding technology," Materials World, vol. 7, no. 12, pp. 751-753, 1999.

[11] Y. X. Gan, D. Solomon, and M. Reinbolt, "Friction stir processing of particle reinforced composite materials," Materials, vol. 3, no. 1, pp. 329-350, 2010.

[12] M. Jariyaboon, P. Møller, R. E. Dunin-Borkowski, S.-I. In, I. Chorkendorff, and R. Ambat, "The effect of atmospheric corona treatment on AA1050 aluminium," Corrosion Science, vol. 52, no. 6, pp. 2155-2163, 2010.

[13] I. Topic, H. W. Höppel, and M. Göken, "Friction stir welding of accumulative roll-bonded commercial-purity aluminium AA1050 and aluminium alloy AA6016," Materials Science and Engineering A, vol. 503, no. 1-2, pp. 163-166, 2009.

[14] H. N. B. Schmidt, T. L. Dickerson, and J. H. Hattel, "Material flow in butt friction stir welds in AA2024-T3," Acta Materialia, vol. 54, no. 4, pp. 1199-1209, 2006.

[15] M. Jariyaboon, A. J. Davenport, R. Ambat, B. J. Connolly, S. W. Williams, and D. A. Price, "The effect of welding parameters on the corrosion behaviour of friction stir welded AA2024-T351," Corrosion Science, vol. 49, no. 2, pp. 877-909, 2007.

[16] H. Li, D. MacKenzie, and R. Hamilton, "Parametric finite-element studies on the effect of tool shape in friction stir welding," Proceedings of the Institution of Mechanical Engineers B: Journal of Engineering Manufacture, vol. 224, no. 8, pp. 1161-1173, 2010.

[17] M. M. Attallah and H. G. Salem, "Friction stir welding parameters: a tool for controlling abnormal grain growth during subsequent heat treatment," Materials Science and Engineering A, vol. 391, no. 1-2, pp. 51-59, 2005.

[18] E. A. El-Danaf, M. M. El-Rayes, and M. S. Soliman, "Low temperature enhanced ductility of friction stir processed 5083 aluminum alloy," Bulletin of Materials Science, vol. 34, no. 7, pp. 1447-1453, 2011.

[19] S. P. Vaze, J. Xu, R. J. Ritter, K. J. Colligan, J. J. Fisher Jr., and J. R. Pickens, "Friction stir processing of aluminum alloy 5083 plate for cold bending," Materials Science Forum, vol. 426-432, no. 4, pp. 2979-2986, 2003.

[20] M. Reis, R. Louro, P. J. Morais, L. Santos, and H. Gouveia, "Microstructural characterisation of $5083 \mathrm{Al}$ alloy joints friction stir welded," Materials Science Forum, vol. 514-516, no. 1, pp. 510515,2006

[21] G. Çam, S. Güçlüer, A. Çakan, and H. T. Serinda, "Mechanical properties of friction stir butt-welded Al-5086 H32 plate," Materialwissenschaft und Werkstofftechnik, vol. 30, no. 2, pp. 151-156, 2008.

[22] M. Merzoug, M. Mazari, L. Berrahal, and A. Imad, "Parametric studies of the process of friction spot stir welding of aluminium 6060-T5 alloys," Materials and Design, vol. 31, no. 6, pp. 30233028, 2010.

[23] V. Fahimpour, S. K. Sadrnezhaad, and F. Karimzadeh, "Corrosion behavior of aluminum 6061 alloy joined by friction stir welding and gas tungsten arc welding methods," Materials and Design, vol. 39, pp. 329-333, 2012.

[24] P. A. Colegrove and H. R. Shercliff, "Development of Trivex friction stir welding tool part 1-two-dimensional flow modelling and experimental validation," Science and Technology of Welding and Joining, vol. 9, no. 4, pp. 345-351, 2004.

[25] M. L. Santella, T. Engstrom, D. Storjohann, and T.-Y. Pan, "Effects of friction stir processing on mechanical properties of the cast aluminum alloys A319 and A356," Scripta Materialia, vol. 53, no. 2, pp. 201-206, 2005.

[26] C. J. Hsu, P. W. Kao, and N. J. Ho, "Ultrafine-grained $\mathrm{Al}^{-\mathrm{Al}_{2} \mathrm{Cu}}$ composite produced in situ by friction stir processing," Scripta Materialia, vol. 53, no. 3, pp. 341-345, 2005.

[27] E. R. I. Mahmoud, M. Takahashi, T. Shibayanagi, and K. Ikeuchi, "Wear characteristics of surface-hybrid-MMCs layer fabricated on aluminum plate by friction stir processing," Wear, vol. 268, no. 9-10, pp. 1111-1121, 2010.

[28] A. Emamian, S. F. Corbin, and A. Khajepour, "In-situ deposition of metal matrix composite in Fe-Ti-C system using laser cladding process," in Metal, Ceramic and Polymeric Composites for Various Uses, J. Cuppoletti, Ed., InTech, 2011.

[29] J. Zhang, Z. Fan, Y. Q. Wang, and B. L. Zhou, "Microstructural development of $\mathrm{Al}-15 \mathrm{wt} . \% \mathrm{Mg}_{2} \mathrm{Si}$ in situ composite with mischmetal addition," Materials Science and Engineering A, vol. 281, no. 1-2, pp. 104-112, 2000.

[30] Y. Chen and D. D. L. Chung, "In situ Al-TiB composite obtained by stir casting," Journal of Materials Science, vol. 31, no. 2, pp. 311-315, 1996.

[31] D. Yadav and R. Bauri, "Fabrication of metal particles embedded aluminum matrix composite by friction stir processing (FSP)," AIP Conference Proceedings, vol. 1315, pp. 51-57, 2011.

[32] A. Kurt, I. Uygur, and E. Cete, "Surface modification of aluminium by friction stir processing," Journal of Materials Processing Technology, vol. 211, no. 3, pp. 313-317, 2011.

[33] Z. Y. Ma, "Friction stir processing technology: a review," Metallurgical and Materials Transactions A: Physical Metallurgy and Materials Science, vol. 39, no. 3, pp. 642-658, 2008.

[34] K. J. Hodder, H. Izadi, A. G. McDonald, and A. P. Gerlich, "Fabrication of aluminum-alumina metal matrix composites via cold gas dynamic spraying at low pressure followed by friction stir processing," Materials Science and Engineering A, vol. 556, pp. 114-121, 2012.

[35] A. Pirondi and L. Collini, "Analysis of crack propagation resistance of $\mathrm{Al}-\mathrm{Al}_{2} \mathrm{O}_{3}$ particulate-reinforced composite friction stir welded butt joints," International Journal of Fatigue, vol. 31, no. 1, pp. 111-121, 2009.

[36] A. H. Feng, B. L. Xiao, and Z. Y. Ma, "Effect of microstructural evolution on mechanical properties of friction stir welded AA2009/SiCp composite," Composites Science and Technology, vol. 68, no. 9, pp. 2141-2148, 2008.

[37] Z. Fan, A. P. Miodownik, L. Chandrasekaran, and M. WardClose, "The Young's moduli of in situ Ti/TiB composites obtained by rapid solidification processing," Journal of Materials Science, vol. 29, no. 4, pp. 1127-1134, 1994.

[38] M. Raaft, T. S. Mahmoud, H. M. Zakaria, and T. A. Khalifa, "Microstructural, mechanical and wear behavior of A390/ graphite and $\mathrm{A} 390 / \mathrm{Al}_{2} \mathrm{O}_{3}$ surface composites fabricated using FSP," Materials Science and Engineering A, vol. 528, no. 18, pp. 5741-5746, 2011.

[39] K. Surekha, B. S. Murty, and K. Prasad Rao, "Comparison of corrosion behaviour of friction stir processed and laser melted AA 
2219 aluminium alloy," Materials and Design, vol. 32, no. 8-9, pp. 4502-4508, 2011.

[40] W. Xu and J. Liu, "Microstructure and pitting corrosion of friction stir welded joints in 2219-O aluminum alloy thick plate," Corrosion Science, vol. 51, no. 11, pp. 2743-2751, 2009.

[41] E. Bousquet, A. Poulon-Quintin, M. Puiggali, O. Devos, and M. Touzet, "Relationship between microstructure, microhardness and corrosion sensitivity of an AA 2024-T3 friction stir welded joint," Corrosion Science, vol. 53, no. 9, pp. 3026-3034, 2011.

[42] X. Li and M. J. Starink, "Analysis of precipitation and dissolution in overaged 7xxx aluminium alloys using DSC," Materials Science Forum, vol. 331-337, pp. 1071-1076, 2000.

[43] B. Zahmatkesh, M. H. Enayati, and F. Karimzadeh, "Tribological and microstructural evaluation of friction stir processed Al2024 alloy," Materials and Design, vol. 31, no. 10, pp. 48914896, 2010.

[44] S. Jerome, S. Bhalchandra, S. Babu, and B. Ravisankar, "Influence of microstructure and experimental parameters on mechanical and wear properties of Al-TiC surface composite by FSP route," Journal of Minerals and Materials Characterization and Engineering, vol. 11, no. 5, pp. 493-507, 2012.

[45] R. M. Mahamood, E. T. Akinlabi, M. Shukla, and S. Pityana, "Characterization of laser deposited Ti6A4V/TiC composite," Journal of Lasers in Engineering. In press. 

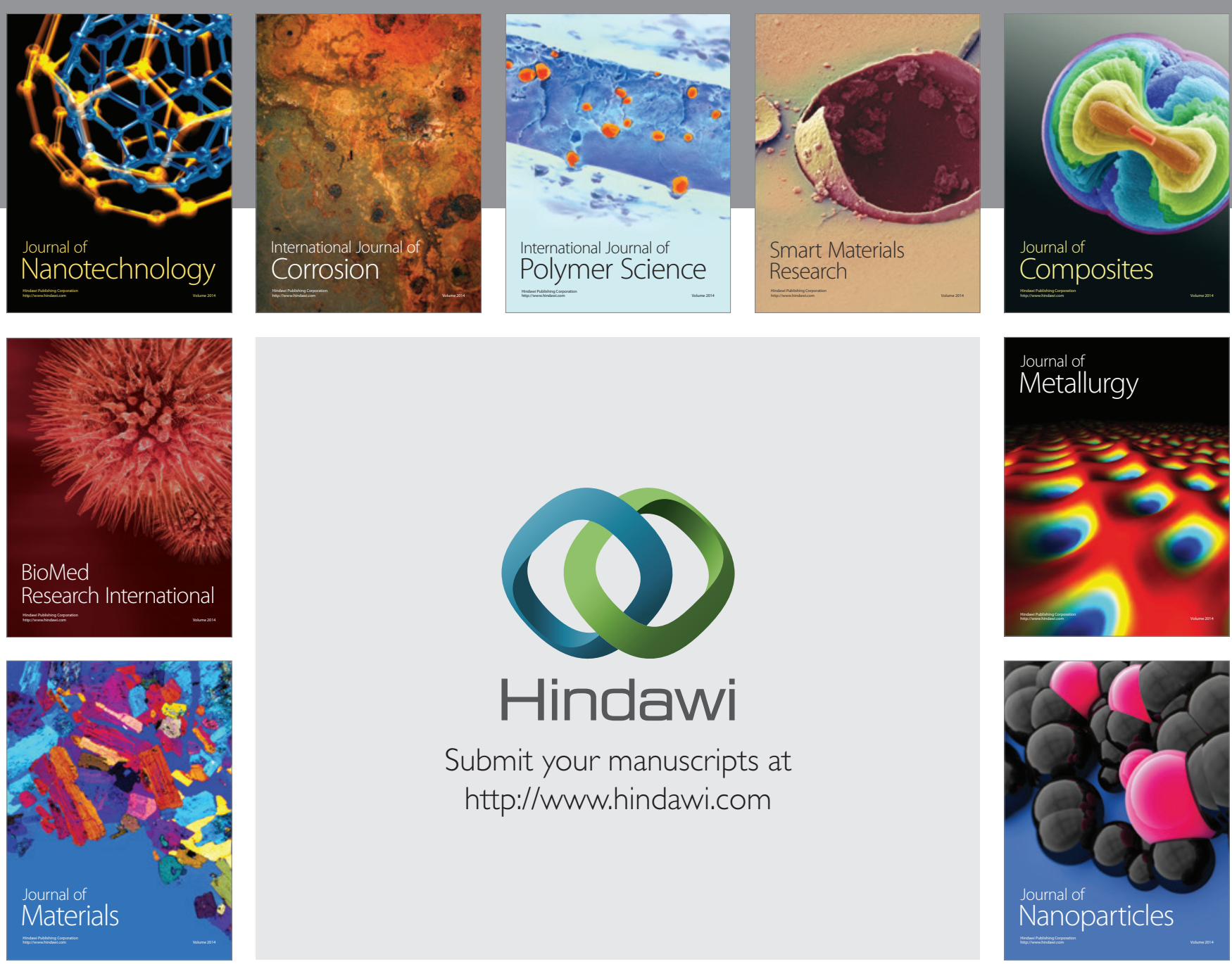

Submit your manuscripts at http://www.hindawi.com
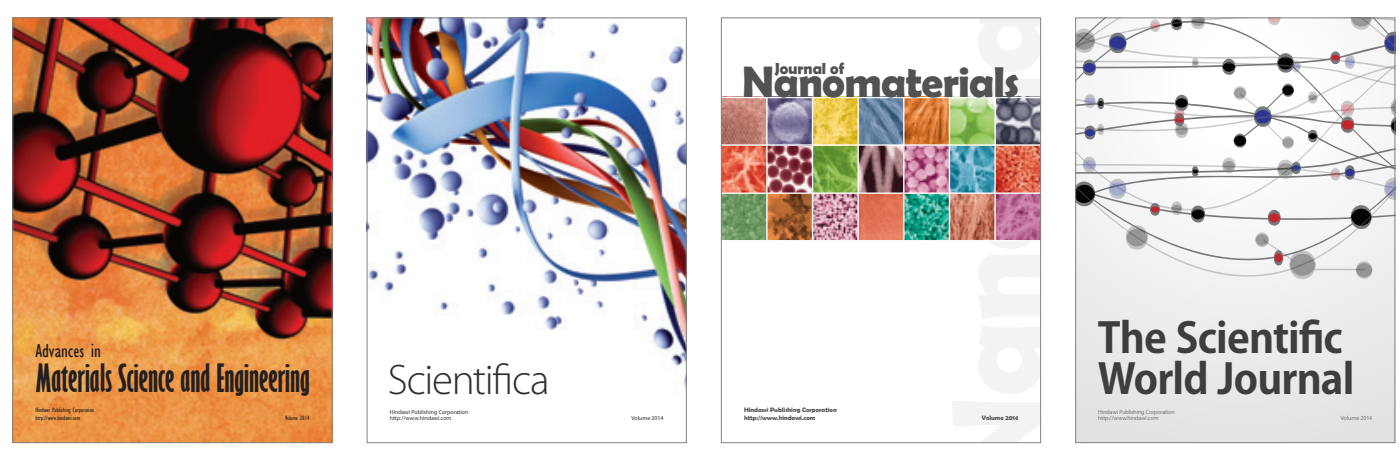

\section{The Scientific World Journal}
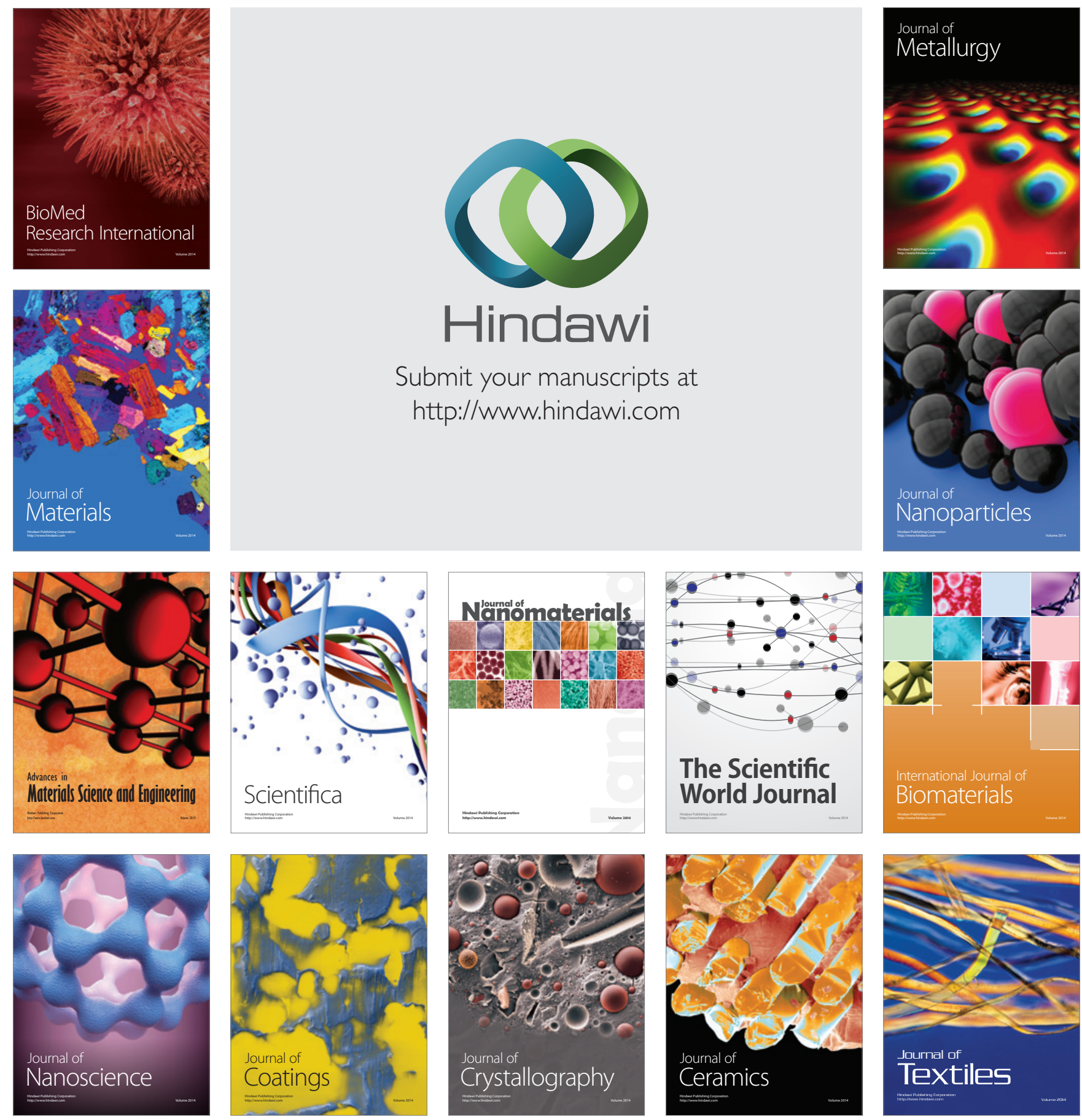